\title{
JD17
}

\section{History of Oriental Astronomy}

Chairpersons and Editors: S. M. R. Ansari \& S. J. Dick 


\title{
ON THE EARLIEST STAGE OF CHINESE ASTRONOMY: 3 HYPOTHESES
}

\author{
Y. MAEYAMA \\ University of Frankfurt, D-60054, Frankfurt am Main, Germany
}

With the achievements obtained in the last few years, in particular most recently, I arrived at the following three hypotheses which seem to combine some major problems of ancient Chinese astronomy on a common historical basis.

\section{The four cardinal points of the compass, the Northern Dipper and the Pole-Star: the Quintuple}

Since the new excavation of the no. 45-tomb in P'u-yang, Ho Nan, China, in 1987 (ca. 4000 B.C.; cf. Feng Shi), it has generally been maintained that at that time the Chinese were already in possession of a conception of the four cardinal points of the compass, as symbolized by
a dragon
East, where the Sun and Moon rise,
a tiger
West, where the Sun and Moon set,
an arched frame of the tomb
South, where the celestial bodies culminate,
the Northern Dipper, (Pei) Tou
North.

Yet the Northern Dipper, figured with numerous shells and two pieces of long bones, shows its sharp tip to the south. This tip, I claim, represents the then Pole-Star ( $\alpha$ Dra), the only unmovable point in the whole Universe, and the original Northern Dipper, (Pei) Tou, had therefore consisted of the Seven Stars $(\alpha-\eta \mathrm{Ma})$ - and probably some others $(\beta, \gamma, \theta$ Boo $)$ - and the Pole-Star ( $\alpha$ Dra). Thus, from those remote times onwards the Chinese had consistently been orientated in the equatorial coordinate-system.

From this it will follow that the structural basis of the Universe, the Quintuple - four cardinal points of the compass and the Pole-Star - must have been established already at that time (ca. 4000 B.C.), long before the 14 cent. B.C., the epoch I had believed to have deduced from the ancient bone inscriptions [Maeyama (1992), ch. 5].

This hypothesis will farther lead us to connect some fundamental elements of ancient China hitherto unexplained (Tou, Ti, Tu):

1. Tou the Northern Dipper, worshiped as a celestial deity (attested in the bone inscriptions [Xu Zhen-tao et al.])

2. $\mathrm{Ti}$ the highest Deity (bone inscriptions, passim)

3. Pole-Star Identified as "Ti", the highest Deity [Maeyama (1992), ch. 5]

4. Emperor, $\mathrm{Ti}$ worshiped as the highest human existence in association with the highest Deity, Ti

5. Tu Earth's God at the World's center, later coupled with the celestial Deity, $\mathrm{Ti}$, as a consequence of the correspondence between macro- and microcosm

6. Ssuma Chhien's description of the Northern Dipper (Tou) as the celestial wagon of the Emperor (Ti) moving around the celestial center Ti, the Pole-Star [Shih Chi (Historical Records), ch. Thien Kuan]

Thus, my hypothesis above seems to reconfirm the existence of the most fundamental core of Chinese mythology as later recorded by Ssuma Chhien (ca. -100), the identity of the highest divin- 
ity as developed in the course of four millennia in association with the Northern Dipper, the Pei Tou:

the only unmovable point in the Universe - North Pole, Pole-Star - the highest God Ti - the later Emperor Ti - Earth's God at the World's center, Tu.

\section{The two cardinal points of the compass, East and West}

The sovereignty of the two cardinal points, East and West, over the other two, South and North, can historically be followed parallel to - but still farther into a more archaical stage than - their development in the West [Maeyama, presented at the Seoul-Congress, 1966].

Now according to my new interpretation, the symbols of the two Direction-Gods, East and West, originally had special meanings and were transmitted at the latest from -14 cent. onwards tenaciously for many centuries:

East $\psi^{4}$

Direction-God of East, Hsi (bone inscriptions), to split a tree with an axe into two pieces: A covenant between man and God must have been recorded on each of the two sides. This and the symbol $d p$ for "to offer, to cut through the offering into two" must have been ultimately related.

West

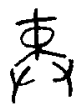

Direction- (Wind)-God of West, I (bone inscriptions): The symbol represents a cock with its two wings bound together in order to cut through the neck. The cock's blood was used to consecrate the holy vessels as often found in bronze inscriptions. This symbol must have originated from the Bird Star, the celestial messenger of the highest Deity, $\mathrm{Ti}$, at the New Year for its first visible setting at the western horizon at dawn, the so-called cosmical setting (cf. 3 . below).

\section{The Bird Star, Niao Hsing, and the origin of the 28 Lunar Mansions}

Although some remarkable stars such as Tou, the Northern Dipper, and Huo ( $\alpha$ Sco) had been known, the Chinese chose the star $\alpha$ Hya as a particular star for combining the macro- and microcosm in time and space:

Time: for its cosmical setting at around the winter-solstice heralding the New Year,

Space: for its rising and setting precisely at the two cardinal points, East and West.

Since the New Year was considered as the celestial message from the highest divinity $\mathrm{Ti}$, the Chinese called that star by the name "Bird Star", Niao Hsing. As shown above, the Direction (Wind)-God of West must have been originally related to the "Bird Star".

Since the Bird Star, $\alpha$ Hya, was approximately on the line, Pole Star (later $\kappa$ Dra) $-\alpha$ UMa (the first star of the Northern Dipper), and further, since the equatorial extension of this constellation nearly covered a quadrant of the celestial sphere, the Chinese divided the sphere into four parts corresponding to the four cardinal points of the compass, all based on the Bird Star and the Northern Dipper. And later they further divided each quadrant into seven parts by means of the Northern Dipper. This is a rough sketch of the apparent origin of the so-called 28 Lunar Mansions $[4 \times 7=28$; cf. Maeyama (1992), ch. 6].

\section{References}

Feng Shi: Astronomical investigation of the tomb n. 45 at the water bank of P'u-yang, Ho Nan (Chinese). Wenwu (1990), III, 52-60, 69.

Maeyama, Y. (1992): The Four Cardinal Points of the Compass and the Chinese Lunar Mansions. The evolution of positional astronomy in ancient China. J.W. Goethe-Univ., IGN Preprint, Series No. 29.

Maeyama, Y. (1995): The stellar reference-points in ancient China and the evolution of positional astronomy. East Asian Science: Tradition and Beyond, K. Hashimoto et al. (eds.), Osaka, 385-394.

Maeyama, Y.: The cardinal points of the compass in ancient China. To appear in the Proceedings of the 8th International Conference on the History of Science in East Asia, Seoul, 1966.

Xu, Zhen-tao - Yau, K.K.C. - Stephenson, F.R.: Astronomical records on the Shang dynasty oracle bones. Archaeoastronomy 14 (1989), S61-S72. 